\title{
Review of protection aspects of microgrid devices
}

\author{
Ashoke Kumar Basu \\ Department Electrical Engineering, The Neotia University, India
}

\section{Article Info}

Article history:

Received Aug 9, 2020

Revised Mar 20, 2021

Accepted Apr 2, 2021

\section{Keywords:}

Distributed energy resources

Islanded mode

Microgrid protection

Point of common coupling

Power inverter

\begin{abstract}
A microgrid is required to provide reliable, quality and efficient supply of both electricity and heat demands to its customers when operates either in autonomous or in grid-connected modes. In this context, it is most important to address a comprehensive protection scheme of the microgrid suiting both the modes of operations. This paper concentrates on the impacts of various devices, like distributed energy resources (DERs), transformers, switches, microgrid topology, communication type, grounding type, to name a few, on the microgrid protection systems. The paper reviewes previous works for the various aspects, like characteristics, construction, of these devices in the light of protection. This review-work is useful for future research in the field of microgrid protection as well as in the selection of its devices.
\end{abstract}

This is an open access article under the CC BY-SA license.

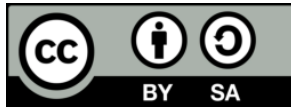

\section{Corresponding Author:}

Ashoke Kumar Basu

Departmen Electrical Engineering

Neotia University

20/1, Khanpur Road, Kolkata 700047, India

Email: ashokekumarbasu@gmail.com

\section{NOMENCLATURE}

DER: distributed energy resources

DG: distributed generator/ generation

ES: energy storage

C-DG: converter-based distributed generator

D-DG: directly-coupled distributed generator

PCC: point of common coupling

FREEDM: future renewable electric energy delivery and management

THD: total harmonic distortion

\section{INTRODUCTION}

Besides many devices of a microgrid, most important are DERs (which include ESes as well as DGs of both C-DG and D-DG types), transformers, lines and different loads. A microgrid can be an independent AC or DC networks or a combination thereof. AC distribution networks may be of individual or any combination of single- or three-phase, low-voltage (LV) or medium-voltage (MV), power frequency or even a high frequency AC (HFAC) grid. Microgrid can flip-flop partly/fully in either of normal (grid-connected) or autonomous modes. The Figure. 1 represents a sample microgrid, where the microgrid is a combination of various zones of DC, AC, or even a HFAC grid [1], [2]. A DC microgrid (Zone I) is a distribution system comprising of DC loads, ES elements, and DG resources of DC output voltages like solar PV, fuel cell. In an AC microgrid (Zone II), LV/MV AC buses connect AC loads to AC resources (like microturbine, diesel 
generators). AC buses can also be found application with DC devices but through bidirectional converters. The HFAC microgrid (Zone III) requires universal active power line conditioner (UPLC) to interconnect to the LV/MV AC buses. Adoption of this system is to control active and reactive power flows in either direction of the microgrid. The converters used in the DC microgrid are of the DC/AC type and connect the DC microgrid to the LV/MV AC buses. Direct connection of renewable-DERs into the DC buses has two positive effects-firstly, increase the overall efficiency of the network, due to reduction in the number of converters by a single one and reducing the requirement of energy transforming as DC loads are supplied directly, and secondly, increases the power quality of the network. HFAC systems with frequencies ranging from $400 \mathrm{~Hz}$ to $20 \mathrm{kHz}$ are currently under trial for power distribution systems. The HFAC system has, in general, the advantages of small in size, higher power density, and modular but for application in microgrids can cause high power losses and voltage drops along the line [3], [4]. As per references [5], [6], the C-DG microgrids responds slowly and ES is necessary for this type of microgrids where loads are mostly sensitive and power quality is concerned. In the grid-connected mode, ES may ensure load leveling and reducing the power exchange with the network which makes the system operation more efficient and flexible. ES may enhance DER penetration and contribute to better quality of energy delivery to customers. A composite ES system is proposed to meet the control of ES and to ensure successful transition to islanded mode as well. This composite ES system contains both high energy density storage battery and high-power density storage ultra capacitor [1]-[6].

In the Figure 1, the dashed lines indicate interconnection of ' $\mathrm{CBs}$ ' by communication network. The symbol ' $\mathrm{CB}$ ' in Figure 1 is a combination of various devices, like circuit breakers, intelligent electronic devices (IEDs), relays-as per the demand of protection requirements. Microgrid central controller (MGCC) has a central protection center (CPC) unit inside, which control ON/OFF of CBs by sending/receiving signals over the communication network [7]. An appropriate designing of microgrid protection system is meant to select its proper devices. This design faces two important problems-firstly, dynamic nature of microgrid, arising due to connection or disconnection of its loads and/or DER units at any time, secondly microgrids operation in both grid-connected and autonomous modes with different short-circuiting currents. A comprehensive scheme should be designed to protect the network in both modes. Again, increasing connections of various types and sizes of DERs at the feeders in the distribution systems have laid challenging demands on feeder protections. DGs have different types and characteristics. Each type has different protection aspects of short circuit current and coordination. Switches (including PCC), transformers, feeders have different types as per their usages and each type has role on protection. Topology is one of the most important factors on which protection strategies of microgrid depends. The microgrid spans, usually, a small area and the communication system is, generally, used either of pilot wires types or optical fibers types or the Ethernet types. Communication system is the backbone of the microgrid protection. Fault current limiter (FCL) and grounding system have also been taken into consideration due to their usage in protection function [7], [8].

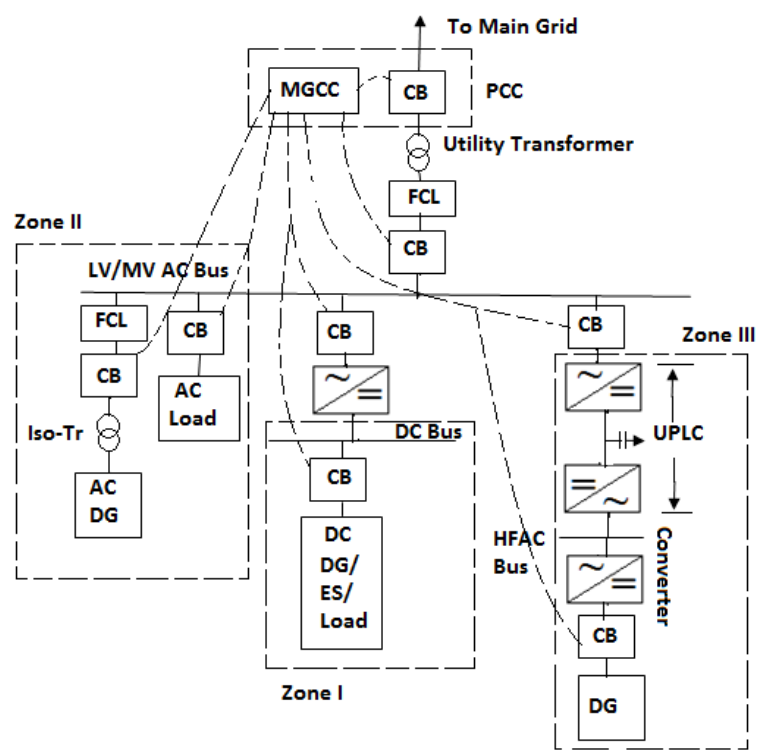

Figure 1. Sample microgrid: Composite structure with DC-, AC- and HFAC- systems 
In the present paper the author has focused, mainly, on the protection aspects of the constituent devices of microgrids and reviewed researchers' works to cast light on this topic. The present survey is organized into three sections. Following the section 1 on introduction, section 2 is divided into seven subsections respectively on "DERs and power inverters", "Point of common coupling (PCC)", "Transformers", "feeders/branches and topology", "switches-circuit breakers, reclosers, sectionalisers and fuses", "communication devices", and "other devices". Each sub-section is, again, divided as per relevance to microgrid protection. Section 3 draws "conclusion". Lastly, acknowledgement and references are included.

\section{DEVICES AND PROTECTIONAL ASPECTS}

Microgrids are composed of both main/essential devices for grid formation, like DERs, transformers, lines, loads and other auxiliary/desirable components, like protective devices, controllers. The auxiliary/desirable components are used for fault free running of each essential device, as a whole, the overall microgrid, so that the customers are supplied with uninterrupted quality of power. Each of these essential devices of microgrids has various construction and characteristics features, which have impacts on the microgrid protection. The present author has reviewed the researchers' works to focus on these devices in the light of microgrid protection.

\subsection{DERs and power inverters}

Most important component of a microgrid is its DERs, which include both DGs and ESes. Power inverters are used to connect DGs and ESes to the microgrid bus. Each such device is reviewed separately in the following sub-sections.

\subsubsection{DGs}

In a microgrid, DGs can be classified as converter-based (C-DGs) and directly-coupled (D-DGs). Synchronous and asynchronous generators are D-DGs and they are coupled to the rotating machines, such as diesel engines, microturbines, and wind turbines. Whereas C-DGs are both static machines like solar PV modules, Fuel cells and rotating machines like wind turbines, microturbines [4]. The C-DGs are of two types current-controlled and voltage-controlled. The amount of fault current supplied by these DGs during a fault is most important consideration in microgrid protection strategy [9]. Short circuit characteristics vary with the types of DGs. D-DGs are characterized by high short-circuit current contribution that may reach 10 per unit (p.u.) of their respective rated current and this current depends on the reactance of the generator and connecting transformer. Whereas, C-DGs have limited contribution to short-circuit currents of up to 4 p.u. of the rated current. Asynchronous generators do not have their independent excitation systems. So, there is a rapid decay of their fault currents below the rated current and it poses difficulty for a relay to pick up the fault [10], [11]. A crowbar-resistor system is commonly used to protect the rotor circuit of doubly-fed induction generators (DFIG) and power converters from overvoltage and thermal breakdown under faulty situations and these DFIGs behave like the conventional asynchronous generators, with a large initial current that quickly decays [11]-[13]. Both synchronous and asynchronous DGs reduce operation time of over current relays, but the impact of asynchronous DGs, as non-synchronization type, outweighs the synchronous DGs. Synchronous or asynchronous-based DGs have an uncontrolled current output during faults whereas CDGs have current output dependent on their control method rather than the type of the generator for instance, PV system is dependent on maximum power-point tracker (MPPT) [1], [4], [9], [14], [15].

There are usually two control schemes of C-DG unit's d-q control and a-b-c control. In the a-b-c control each phase is controlled separately, but not in the case for $\mathrm{d}-\mathrm{q}$ control. When fault is occurred in one phase, control loop limits current of all phases (both healthy and faulty) in d-q control, but the currents of healthy phases will remain constant in a-b-c control. This helps the over current relay to sense and subsequently, clear the fault in a-b-c control. Thus, the authors of refs [4] and [16] suggest double control strategy $\mathrm{d}-\mathrm{q}$ control in normal mode and $\mathrm{a}-\mathrm{b}-\mathrm{c}$ control in faulty situations. Again, voltage-controlled C-DGs show a different fault characteristic from that of current-controlled one. The voltage-controlled C-DGs are unable to precisely regulate their output current and are susceptible to short circuit whereas current-controlled ones have inability to maintain their terminal voltage and are vulnerable to under-voltage faults [4], [5], [16].

The coordination is another important aspect of micogrid protection where DERs have an important role. For any given microgrid network, several aspects, such as optimum locations, sizes, maximum DG penetration levels, play role for loss of protection coordination [17]-[19]. For non-violation of protection coordination, the researchers have proposed various ways, such as: i) to adjust the distance between the curves of over current relays in operation for adding of DG units, ii) for finding optimal location of a DG unit, and iii) the maximum capacity of a DG unit [20], [21]. An index is defined and according to this index, adds DG resources to the microgrid as long as it does not affect coordination of over current relays [17]-[22]. 
Dynamic performance of a microgrid is a major topic in protection. During a fault, the generating units must supply sufficient short-circuit current to ensure correct coordinated operation of the protection devices. Again, following fault clearance, the DGs should recover and supply active power as fast as possible without undue oscillations, and further to support quick voltage recovery, the DGs requires to supply reactive power, or to reduce reactive power consumption. DG manufacturers introduced the control techniques to meet the active-reactive requirements. However, the control techniques have impact on the short circuit behavior of the various types of DGs [23], [24]. The control techniques are not standardized and have introduced uncertainty in the fault current contribution of the DGs - it is apparent that integration of DGs requires protection that is capable of maintaining protection coordination under bi-directional and variable power flow conditions. The protection must also operate correctly under the conditions of unpredictable fault currents [11], [13], [25], [26]. Non-rotating DG penetration, especially of PV, has the effect of reduction of the effective system inertia leading to reduced dynamic performance of microgrid [11], [27]. Balancing fault current for all possible situations of microgrid is complicated and highly expensive [4], [28]. There are grid codes for operation of DGs, namely, - i) the threshold voltage - above which the DG to remain connected, ii) the maximum current capability of the inverter-based DG, iii) provision of the maximum reactive current of the DG for voltages below $0.5 \mathrm{pu}$ [14]. As per the new grid codes the DGs continue connected for a short duration under fault conditions. It demands anti-islanding protection and fault ride through (FRT) capability to be considered with DG unit. ESes and photovoltaic (PV) systems, due to their low fault ride through (FRT) capabilities, face difficulties to clear all shunt and high impedance faults (HIFs) in radial and mesh structures. And accordingly, variety of low voltage ride through (LVRT) standards has been framed by the technical community [29]-[34].

\subsubsection{ES systems}

There are usages of energy storage (ES) devices in microgrids-battery, ultra capacitor, flywheel, to name a few. In general, energy storage would be connected to the microgrid through an inverter interface. ESes improve power quality via frequency regulation [29]. They are beneficiary for microgrid owners in many ways: i) to generate most efficient and least expensive power, ii) to provide uninterrupted power to critical loads, and to supply the emergency power during storms, equipment failures, or other fouls, iii) to ensure seamless transfer to the islanded mode, and iv) to enhance flexibility in power generation, delivery, and consumption [6], [35]. Large-scale integration of ESes increases the efficiency of main grids - in turn, reduces operation cost and emissions and also, increases power reliability [6].

ESes, preferentially batteries, is connected to the microgrid to allow the use of conventional overcurrent protection devices [36]-[38]. The battery operation is limited by the fault current. To avoid their damage, its operation is stopped instantly when fault current exceeds an acceptable threshold current. These devices have the disadvantage of high cost. The fault current amplitude of capacitor-ES is very high with a short time constant and the fault current amplitude depends on the capacity of the capacitors. Flywheels and batteries-ESes can be used to provide supplementary short-circuit level to the network [12], [39], [40]. Flywheel ES is coupled to inverter-interfaced DG to supply a significant current. Flywheel ES is very useful for critical load, especially when coupled with dispatchable DG such as diesel generators. As flywheels are expensive and require a sophisticated control scheme for coordination with DG in a microgrid - not every inverter-interfaced DG unit is equipped with a flywheel system [41], [42].

\subsubsection{Power inverters}

Power inverters, broadly converters, have many functions to serve, when is used in the microgrid, mainly, to control power flows of DERs, to stabilize voltage and frequency of the microgrid, and to convert the operating voltage from DC into AC and vice-versa [12], [43], [44]. There are two modes of control of DC/AC inverter: i) V-f mode during the autonomous operation to stabilize the microgrid voltage and frequency and ii) P-Q mode during the grid-connected operation. The latter mode adjusts the injection of active and reactive power flows into the main grid. Most of the power inverters require to have the capability to limit fault currents to avoid their undesirable damage and digital relays are an effective protection solution for the DC/AC inverters [12], [36]. For protection from the faults of power inverters, the devices, like fuses, no-fuse circuit breakers, and protective relays in addition to power- semiconductor switches are used at the AC side. Different types of power semiconductor switches have different characteristics and require different protection schemes. The IGBT protection is much faster, operates in the order of $\mu$ sec, and allows only 1.2 to 1.8 times of rated current. On the contrary, SCR switches are much slower than IGBTs. DESAT (desaturation) protection for identifying a fault condition and a short circuit in an IGBT is used in the protection of inverters. IGBT will be at de-saturation condition if collector to emitter voltage exceeds above 5 to 8 volts and the gate to emitter voltage is high. It has been pointed out that damage to the semiconductor devices of 
the converter is arising due to heavy discharge of dc side filter capacitor during short circuit faults. It is suggested a modulated low fault energy (MLE) protection scheme for DC distribution system [45]

As an exception, if the inverters have no ability to limit the fault currents, then fuses and no-fuse circuit breakers must have the capability to protect the inverters against line-to-line and three-phase faults in the un-grounded LVAC microgrid. Different operating principles of the protective relays, not based on high fault current, are selected against different faults and different grounding types of microgrids, such as ungrounded, uni-grounded, and multi-grounded. Fault currents available are very less, only 2-3 times the full load current or even less depending on control method of converter [19], [45], [46]. There is a proposal to adopt a current-limit method of converter control by reducing the voltage in the faulty phase(s) but to keep the voltage of healthy phases unaltered. It is reported that a flywheel system with inverter-interfaced DG is suited to supply a significant current [19], [29], [30].

\subsection{Point of common coupling (PCC)}

The microgrid jurisdiction starts from separation switch (CB) of PCC to downward, see Figure 1. The PCC is, usually, located at the primary side of utility transformer and is the point of interconnection/separation with main (or utility) grid [47], [48]. It accommodates central controller, protective relays/sensing units, synchronizing unit and separation switch. The central controller consists, mainly, of two modules-energy management module (EMM) and protection coordination module (PCM), also, called it as central protection unit (CPU) [49]. The central controller produces the informative data set containing the network topology as well as locations and identifiers of protective relays [30], [39].

The DG-utility interconnection functions of PCM are three-folds: i) disconnection of DG from the main grid, if required; ii) protection of the microgrid due to fault current supplied by DGs when the fault and transient overvoltage arisen at the main grid; and iii) protection of DG from the damage, arisen especially due to automatic reclosing [50]-[53]. The sensing units of PCM are several like current sensing unit (CSU), zero crossing detection unit, relay settings updater for adaptive protection system, sensor for under/over (U/O) voltage, loss of grid (LOG) protection schemes [54], [55]. The CSU measures the network currents with the purpose of detecting actual faults and takes more than seven cycles to avoid transient situation of DG reconnection [4], [56]. The under/over frequency of the PCC current waveform is determined by zero crossing detection unit. Rate of change of frequency (ROCOF) relay, with a $1.0 \mathrm{~Hz} / \mathrm{sec}$ threshold, sends a trip signal to the PCC circuit breaker (CB) [4], [8].

After the fault clearance, automatic synchronization unit becomes active for restoration of the main grid reconnection- voltage, frequency and phase angle of both grids must be matched within acceptable limits. Preferably, automatic re-synchronization scheme works with communication network [7], [19], [57], [58]. PCC separation switch is a high-speed breaker. High speed is required to maintain the microgrid stability against faults on the main grid or within Microgrid. Especially, voltage sensitive D-DGs may endanger the Microgrid stability. "Transfer trip" scheme is incorporated in this breaker to avoid nuisance separation and providing fast tripping. For high speed operation, a static switch - either SCR based or IGBTbased is used [19], [45], [57]-[63].

\subsection{Transformers}

A microgrid has a number of transformers for different usage-utility transformer, isolation transformer, and smart transformer. These transformers are three phase or single-phase types. The types of winding connections of the three phase transformers have important effect on the protection type. These transformers are reviewed in the following sections.

\subsubsection{Utility (main) transformer/distribution transformer}

It is, usually, located next to PCC at the microgrid side, see Figure 1. It is a MV/LV transformer for LV microgrid. Regarding transformer connection, the researchers have reported many points. For $\mathrm{Y}-\mathrm{g} / \mathrm{Y}-\mathrm{g}$ transformer connection, there is a flow of zero sequence current in the line. If $\Delta / Y-g$ connection, with delta on the DG-side, is used then flow of zero sequence current in the line will be stopped and SEMI F47 voltage standard will be maintained. The latter connection acts as a self-ground source, but not the former. $\Delta / \mathrm{Y}-\mathrm{g}$ connection is claimed most effective for single-line-to-ground faults on the delta side and loads connected line-to-neutral on the wye side [7], [30], [53], [60], [64]. Researchers, also, reported when fault occurs on the MV side of the transformer, the microgrid is islanded from the PCC, and still fault current is fed by the DGs. It is suggested that relays at the LV side should isolate DGs from the MV system, but continue to supply the local loads [7], [65]. 


\subsubsection{Isolation transformers}

An Isolation transformer is interposed between DG-source branches and common AC buses in the AC microgrid ("Iso-Tr" in Figure 1). It eliminates dc-current components generated by inverter. It is, mainly, a step-up transformer with DER side at lower voltage [12], [36]. Back-feed of overvoltage, relay coordination, unbalanced feeder loads, grounding relaying for feeders, to name a few, are the deciding factors for this transformer connection. Like utility transformer if this transformer is connected in $\Delta / \Delta$ or $\Delta / \mathrm{Y}$-g with DER side delta, then transformer acts as a ground source and no zero sequence current flows through the feeder. This transformer is, also, used to make different configuration of AC microgrids, like 3-phase and 4-wire, 3-phase and 3-wire, 1-phase and 2-wire, or 1-phase and 3-wire [7], [60].

\subsubsection{Smart or solid-state transformers (SST)}

SSTs are three-port power electronic exchanger having three-layer conversions: HVDC link, LVDC link and AC link, see Figure 2. It acts as a solid-state plug-and-play interface. The Massachusetts Institute of Technology (MIT) has selected it as one of the best technologies of 2010 [64]. FREEDM microgrid is a looped one, having renewable DGs, ESes, power electronic devices, and loads of both industrial and residential types. In FREEDM network, there is a problems of bi-directional power flow, unbalancing due to single phase DGs as well as loads, and renewable DGs with DC output. Due to these problems, there arises harmonics, saturation of transformer, poor power factor, to name a few. SSTs take care of these problems, replacing traditional transformers. SSTs can play a crucial role in microgrid protection during overloads and distortions. Its capability and design help minimizing circuit and communication for successful protection strategy [4], [66], [67].

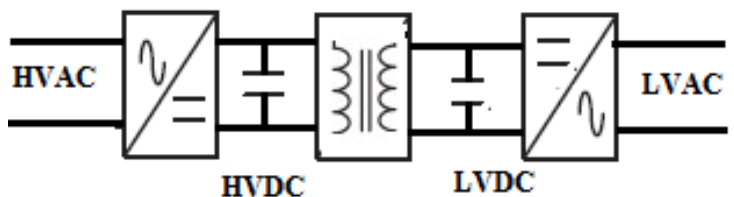

Figure 2. Representation of solid-state transformers (SST)

\subsection{Feeders/branches and topology}

A microgrid has a number of feeders and these feeders are divided into various zones to facilitate protection of the microgrid for both grid-connected and autonomous modes [19]. For zoning of these feeders, it is kept in mind that there is an appropriate balance between DGs and loads in each zone. On autonomous mode, total DG capacity of any zone is to be kept slightly higher than load-reason is to meet maximum load of the zone and to isolate the minimum section of the radial feeder to eliminate the fault. In each zone, there must be at least one largest DG capacity to adjust load frequency. Each zone needs fast operating switches, sub-station breaker, synchronization-check relays, and communication facility [19], [48]. The researchers reported that impedance of a feeder, as measured, varies significantly under different conditions, such as normal operation and faulty conditions. This measured value is, also, different under internal faults, and external faults. In the research works, two types of feeder have been addressed-single-end feeding and double-end. It is reported that measurement of impedance for a single-end feeder is rather simple compared to double-end feeders. In the former (single-end) feeder, the fault resistance added with the real part of the impedance, but for a later (i.e., double-end feeder) the complicacy in the measurement of impedance arises due to type of internal faults and its relationship with fault type, fault current, and fault resistance. Whereas for a solid fault, the measured impedance contains only line resistance and reactance. It is, also, reported if the fault resistance increases, then the measured impedance of the feeder will rise up to a critical point and thereafter decay [68]. As the impedance of the feeders is low on active distributed networks (ADNs), it is not easy to estimate the fault direction under three-phase faults. Also, for un-ground microgrid, there is a shift of neutral point as the fault current in the feeder contains DC offset [68], [69].

\subsubsection{DG-source branches}

The cable has greater impedance than the overhead line. When DG is connected with overhead line feeder, it affects most the grid contribution to the fault current [70]. DGs are of various types such as C-DG and D-DG. Faults in the microgrid feeder are of different types-SLG (single line to ground), line-to-line (LL). Fault current in various sections of the feeders depends on both DG and fault types. As per the researchers, feeder protections utilize sequence current and voltage components (i.e. positive, negative and zero), total 
harmonic distortion levels of phase currents and voltages. Negative sequence current and voltage components and THD levels of current and voltage of faulted phase are reported a significant increase after the fault inception time of 50th second. If short-circuit currents is considered for feeder protections, there arise serious problems like rising of undetected faults, non-coordinated tripping, reduction of reach of relay, failure of fuse saving. C-DG source branches (e.g., the battery-energy storage and micro-turbine source branches) in the microgrid contains power inverters. These power inverters limit the fault currents into the faulted PV-source located at the other branch [8], [12], [36].

\subsubsection{Load branches}

Microgrid loads are of different types, such as static and dynamic loads. Loads act under different conditions of starting, and have different capacities, and power factors. To tackle all these situations, different relay characteristics, such as overcurrent relay, under-voltage relay, negative sequence-based relay, and THD based relay are selected. These relay characteristics are chosen to obtain the high co-ordination, discrimination, reliability and fast operation of the protection system. For load branches high-speed fuses are effectively used in co-ordination with over-current relay. Feeder, wherefrom load branch is brought out, see Figure. 3, has limited current carrying capacity. Load switches are used and have limited carrying capacity, compared to breaker and recloser [12], [36].

\subsubsection{Trunk feeders}

Trunk feeder is the main line (Figure 3). Load branch is not allowed to connect all through the length of AC trunk line. There are various types of faults occurred in the AC trunk line, which are single-line to ground (SLG) faults, double-line to ground (LLG) faults, and line-to-line (LL). For the first two ground faults at the grid-connected mode of a uni-grounded microgrid, fault current flows from faulted location back to the grounded neutral of the distribution transformer. This fault current magnitude varies with the type of DGs - more for the D-DGs than C-DGs. Again, for low impedance LL faults, fault current is high enough to operate over-current relay. The researchers reported that there are significant negative sequence current and voltage components and THD of phase voltage and current helping protection solutions for both un-grounded and uni-grounded microgrids. The THD value at the faulted phase is comparatively more than the healthy phases and helps detect the faults. For negative sequence protection, careful evaluation of its threshold value is important to avoid mal-operation under unbalanced load conditions [12], [36].

\subsubsection{Topology}

Topology is one of the most important factors on which protection strategies in microgrid depends. It affects both the fault current direction and magnitude. The structure of a microgrid is of different typesradial, looped, meshed or mixed. The structure is also an important part of topology. Fault current at different topologies varies and same topology, say loop structure, has different current in different paths and the protective devices on those paths sense different currents [4], [71]. There are several reasons for change of microgrid topology due to various control actions, namely, shedding of loads during peak-hours or addition of DG for energy export to utility for optimum and economical operation of Microgrid [19]. The most crucial challenge in microgrid protection is the uncertainty in microgrid topology [4]. Most presented methods can not cover all operational topologies of microgrid. There is a concept of multi-microgrids which consists of a number of DGs and LV microgrids that are connected to the MV distribution supply. Both radial and looped microgrids must have the capability of protection against different types of faults in addition to single-phase tripping. DC microgrid is comprised of DC loads, energy storage elements, and DG having DC output voltage [4]. Primary protection schemes of radial LV DC microgrid encompass converter, battery, and feeder against pole-to-pole and pole-to-ground faults [2], [72].

\subsection{Switches-circuit breakers, reclosers, sectionalisers and fuses}

Switches, which are commercially available for protection of both DC and AC microgrids, are, mainly, molded-case circuit breakers (MCCB), low-voltage CBs, and isolated-case CBs [2], [4], [73]. Generally, AC breakers are much cheaper than dc breakers. AC breakers depend on the natural zero of AC current. Circuit breaker is used as a separation device at PCC (section 2.2). Procedures for selection of rating of AC and DC switches are not same - due to higher time constant DC microrids need fast acting power electronic switches, such as GTOs, IGBTs, and insulated-gate commutated thyristors (IGCTs), which prevent meltdown of fuse i.e., increase fuse-saving [4], [74]. Such devices have different characteristics, but the solid-state CBs needs to be bidirectional to allow power flow in either direction [75]. 


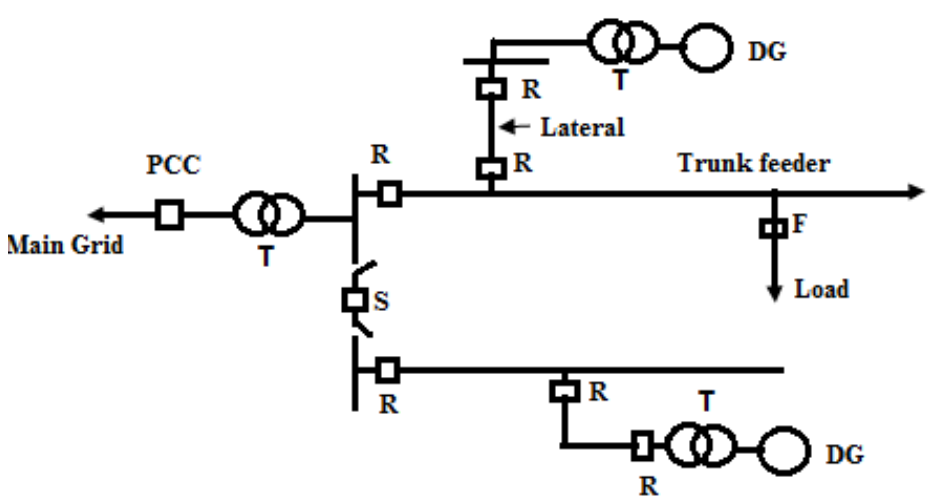

Figure 3. Microgrid layout- R: reclosers, S: sectionalizers, F: fuse, T: transformer

The protection system predominantly uses reclosers, fuses, relays, sectionalisers, see Figure 3. Importance of reclosers arises as $80 \%$ of faults in distribution system are temporary [76]. Coordination among these devices is very important for protection. Reclosers are placed on main feeder and act in coordination with fuse on laterals [11]. The microprocessor-based reclosers have directional property and can support in coordination. Synchronizing problem is solved by disconnecting all downstream DGs. Problems in coordination, also, arise due to high penetration of DGs. Circuit breakers, including reclosers, need incorporation of check-synchronizing function to perform its closing. As per Australian Standard 4777.3 and IEEE Standard 1547, the maximum allowable time for operation of DG's passive anti-islanding protection is, usually, two seconds [30], [31]. Whereas reclosers remain open in the range of hundreds of milliseconds up to seconds. Systematic islanding of microgrid is necessarily to be done after shutting-off of all DG units and it is ensured by anti-islanding protection. Reclosing of reclosers is suggested at the time of out-of-service of all DG units and this will eliminate all possibilities of damages due to unsynchronized closing of reclosers. Hence it is desirable to select recloser time with consideration of DG unit's anti-islanding protection. Unlike reclosers, sectionalizers could not extinguish the fault current, which is associated with its zone of protection. Sectionalisers work in coordination with reclosers. Sectionalizers will open after opening of a number of identified reclosers and an upstream circuit breaker extinct the fault current [30].

\subsection{Communication devices}

There are two concepts of communication architectures-centralized and de-centralized. In the central communication system if computer fails, the protection for the entire distribution system will be disable, but the de-centralized system has an edge over it-with the failure of one node, portion localized the node of the distributed network will be affected. The centralized scheme needs more communication links and hence costs more. The fully de-centralized system has the drawbacks that it handles local information, not acts on system-wide co-ordination. The microgrid spans, usually, a small area and the communication systems are, generally, used either of pilot wires, optical fibers or the ethernet. A communication-based protection schemes requires a central control unit, measurement devices and circuit breakers-all are linked via communication networks (shown in Figure.1). Microprocessor relay for MV microgrids interconnects a microgrid central protection unit (CPU) and the individual relays at each subsection via a communication network. An optical ethernet communication network is proposed by researchers in radial grid-connected microgrid to integrate a protection and control (IPC) unit to the measurement devices, circuit breakers and control units at each bus [39], [72], [78], [79]. Wireless mobile broadband is proposed in works [72], [80] where this communication system is used to connect IEDs and circuit breakers at each bus to the control centre. IEDs are, also, proposed to detect and locate a fault in the distribution network and to facilitate the data communications to a central computer. Algorithm is to be framed to identify the appropriate circuit breakers to trip and clear the fault. Algorithm depends on the current, voltage and directional signals received from remote IEDs to generate trip or block signals that are sent back to the IEDs via the faulted path [11], [26], [81], [82].

The central computer is a part of central protection unit (CPU), which is again a part of MGCC located at PCC. Central computer works as: i) receiving of information about the network topology/configuration and DG status (whether connections or disconnections), ii) accordingly, the settings of the protection devices being adjusted, and iii) lastly maintain coordination between the devices [11], [82], [86]. The centralized scheme is implemented with serial/bus communication and use power-line carrier or 
Ethernet network. The communication protocols used are Modbus, DNP3, IEC 60870-5-101/104, and IEC 61850. On the other hand, decentralized control relies on information exchange between IEDs and use IEC 61850 protocols for decentralized communication. The algorithm requires to suit real-time two-way communication and defends cyber attacks. The algorithm is based on communication infrastructure and estimation. The researchers have addressed loss-of-mains detection, differential protection using systems with communication networks. The researchers have taken challenge of loss-of-mains detection using phasor measurement units (PMUs) and global positioning system (GPS) and differential protection with IEDs using classifier assisted by communication networks based on the IEC 61850 service tracking mechanism [11], [19], [39], [87]-[94].

\subsection{Other Devices}

\subsubsection{Fault current limiters (FCLs)}

FCL is placed near the PCC, see Figure 1. FCL limits the fault current (short-circuit) level - whether fault current from the main grid to the microgrid or by the DGs (synchronous-based distributed generators) in the microgrid towards the main grid. Advantages of the FCLs could, namely, be followed to: "no DG disconnection', 'no up-gradation of relay settings', 'no up-gradation of devices for handling high currents. But impedance of FCL increases with increase in individual DG capacity hence its cost increases. Moreover, transient response of FCL is another concern [18]. There are three types of FCL, namely, super conducting FCL, solid state FCL, electromagnetic FCL [4], [36], [39], [95]. Impact of DG, if negative, is to be minimized by placing FCL, see Figure 1 on the DG branch and over current relays operates at significantly reduced time [4], [96], [97]. FCL becomes a part of a Central Protection Unit (CPU) and a communication system - to monitor the status of microgrid, to predict fault conditions, to program the protection system and update trip value of relays [4], [39], [40]. C-DG uses the protection scheme with an FCL to ensure fault detection without surpassing current ratings [30], [47]. Thyristor-controlled series capacitor (TCSC) type FCL is connected in series with DG unit for only grid-connected mode to limit DG sharing of fault current [98]-[100]. The tie feeder connects upstream and downstream networks-there is a loss of coordination between the upstream and downstream protective relays. To overcome this problem, conventional bidirectional FCLs is replaced by unidirectional fault current limiter (UFCL) [101], [102].

\subsubsection{Grounding}

In the distribution network, $98 \%$ faults are ground faults. Operating principle of fault protection systems of microgrid is dependent on its grounding configurations: multi-grounding, uni-grounding and ungrounding [36]. The outcome of the research informed that TN-S system of grounding solve the problem of detection of fault current in islanding mode with C-DG resources. Whereas with TT and IT systems, protective relays could not distinguish between fault current and load current of the microgrid. To compromise between the over-voltage limit and the reasonable fault-current, proper grounding impedance will be selected [2], [4], [103], [104].

DC microgrid is influenced by grounding scheme, both the transient short circuit current and overvoltage of the DC microgrid are highly affected. Fault detection and protection capabilities are badly changed. A single pole ground fault in an ungrounded (floating) DC microgrid produces low ground current and it is very difficult to detect and locate by different detectors [2], [104]-[106]. Again, resistance grounded system produces a small current and reduced voltage transient during a single pole ground fault. Hence, loads are supplied continuously without interruption. If the system is solidly grounded, then fault could easily be detected and quickly cleared. [2], [105]-[108].

\section{CONCLUSION}

Microgrid is poised for more positive growth in the recent future of deregulated regime. More research is afoot all over the world to usher a reliable form of microgrid. Protection is a most vulnerable aspect of microgrid operation and needs a special attention for uninterrupted/or minimum interruption in the operation of microgrid. The present review is focused on the constituent devices of the microgrid. The present review work addresses the researchers' works in connection with the protection aspects of these devices.

In both normal and islanding modes, the presence of DG units changes the operation of a microgridsuch as change of fault current level, false tripping, blindness of protection, prohibition of automatic reclosing, and unsynchronized reclosing. An appropriate protection system for microgrids requires proper considerations on the key factors, mainly on characteristics, construction, of microgrid devices such as feeder and topology, DGs and transformers, communication system, to name a few from the section 2. A comprehensive review on the various protection plans of these devices has been performed based on the 
proposal by previous authors. The protection strategies have been proposed by the researchers to extend to a general distribution system with multiple types of DGs, different structures or topologies of networks, algorithm with minimum communication requirements, protection against cyber attacks and less impact of communication link failure. Protection coordination strategy operates faster with communication networking. The effects of FCL and grounding/un-grounding on microgrid protection have also been reviewed.

\section{REFERENCES}

[1] TS. Ustun, Cagil Ozansoy and Aladin Zayegh, "Recent developments in microgrids and example cases around the world-a review," Renewable and Sustainable Energy Reviews, vol. 15, no. 8, pp. 4030-4041, 2011, doi: 10.1016/j.rser.2011.07.033.

[2] D. Salomonsson, L. Soder and A. Sannino, "Protection of Low-Voltage DC Microgrids," in IEEE Transactions on Power Delivery, vol. 24, no. 3, pp. 1045-1053, 2009, doi: 10.1109/TPWRD.2009.2016622.

[3] S. Chakraborty and M. G. Simoes, "Experimental Evaluation of Active Filtering in a Single-Phase High-Frequency AC Microgrid," in IEEE Transactions on Energy Conversion, vol. 24, no. 3, pp. 673-682, 2009, doi: 10.1109/TEC.2009.2015998.

[4] S. A. Hosseini, H. A. Abyaneh, S. H. H. Sadeghi, F. Razavi, A. Nasiri, "An overview of microgrid protection methods and the factors involved," Renewable and Sustainable Energy Reviews, vol. 64, pp. 174-186, 2016, doi: 10.1016/j.rser.2016.05.089.

[5] S. Chen, N. Tai, C. Fan, J. Liu, S. Hong, "Sequence-component-based current differential protection for transmission lines connected with IIGs," IET Gener. Transm. Distrib., vol. 12, no. 12, pp. 3086-3096, 2018, doi: 0.1049/iet-gtd.2017.150.

[6] S. Parhizi, H. Lotfi, A. Khodaei and S. Bahramirad, "State of the Art in Research on Microgrids: A Review," in IEEE Access, vol. 3, pp. 890-925, 2015, doi: 10.1109/ACCESS.2015.2443119.

[7] S. Chowdhury, SP. Chowdhury, P. Crossley, Microgrids and Active Distribution Networks. Institution of Engineering and Technology, IET Digital Library: UK, 2009.

[8] R. Ndou, J. I. Fadiran, S. Chowdhury and S. P. Chowdhury, "Performance comparison of voltage and frequency based loss of grid protection schemes for microgrids," 2013 IEEE Power and Energy Society General Meeting, 2013, pp. 1-5, doi: 10.1109/PESMG.2013.6672788.

[9] S. Liu, T. Bi, A. Xue and Q. Yang, "Fault analysis of different kinds of distributed generators," 2011 IEEE Power and Energy Society General Meeting, 2011, pp. 1-6, doi: 10.1109/PES.2011.6039596.

[10] K. Jennett, F. Coffele and C. Booth, "Comprehensive and quantitative analysis of protection problems associated with increasing penetration of inverter-interfaced DG," 11th IET International Conference on Developments in Power Systems Protection (DPSP 2012), 2012, pp. 1-6, doi: 10.1049/cp.2012.0091.

[11] P. T. Manditereza and R. Bansal, "Renewable distributed generation: The hidden challenges-A review from the protection perspective," Renewable and Sustainable Energy Reviews, vol. 58, pp. 1457-1465, 2016, doi: 10.1016/j.rser.2015.12.276.

[12] D. M. Bui, S. L. Chen, K. Y. Lien, Y. R. Chang, Y. D. Lee, and J. L. Jiang, "Investigation on transient behaviours of a uni-grounded low-voltage AC microgrid and evaluation on its available fault protection methods: Review and proposals," Renewable and Sustainable Energy Reviews, vol. 75, pp. 1417-1452, 2017, doi: 10.1016/j.rser.2016.11.134.

[13] T. N. Boutsika and S. A. Papathanassiou, "Short-circuit calculations in networks with distributed generation," Electr Power Syst Res, vol. 78, no. 7, pp. 1181-1191, 2008, doi: 10.1016/j.epsr.2007.10.003.

[14] H. Margossian, G. Deconinck and J. Sachau, "Distribution network protection considering grid code requirements for distributed generation," IET Gener. Transm. Distrib., vol. 9, no. 12, pp. 1377-1381, 2015, doi: 10.1049/ietgtd.2014.0987.

[15] O. Núñez-Mataa, R. Palma-Behnkeb, F. Valenciab, A. Urrutia-Molinab, P. Mendoza-Arayab, and G. JiménezEstévezb, "Coupling an adaptive protection system with an energy management system for microgrids," The Electricity Journal, vol. 32, no. 10, p. 106675, 2019, doi: 10.1016/j.tej.2019.106675.

[16] M. Brucoli and T. C. Green, "Fault behaviour in islanded microgrids," in Proceedings of the 19th international conference on electricity distribution, CIRED, 2007, p. 0548.

[17] I. K. Tarsi, A. Sheikholeslami, T. Barforoushi and S. M. B. Sadati, "Investigating impacts of distributed generation on distribution networks reliability: A mathematical model," Proceedings of the 2010 Electric Power Quality and Supply Reliability Conference, 2010, pp. 117-124, doi: 10.1109/PQ.2010.5550010.

[18] L. K. Kumpulainen and K. T. Kauhaniemi, "Analysis of the impact of distributed generation on automatic reclosing," IEEE PES Power Systems Conference and Exposition, 2004., 2004, pp. 603-608 vol. 1, doi: 10.1109/PSCE.2004.1397623. 
[19] A.A Memon and K. Kauhaniemi, "A critical review of AC Microgrid protection issues and available Solutions," Electric Power Systems Research, vol. 129, pp. 23-31, 2015, doi: 10.1016/j.epsr.2015.07.006.

[20] H. A. Abdel-Ghany, A. M. Azmy, N. I. Elkalashy, and E. M. Rashad, "Optimizing DG penetration in distribution networks concerning protection schemes and technical impact," Electr Power Syst Res, vol. 128, pp. 113-22, 2015, doi: 10.1016/j.epsr.2015.07.005.

[21] S. Chaitusaney and A. Yokoyama, "An Appropriate Distributed Generation Sizing Considering Recloser-Fuse Coordination," 2005 IEEE/PES Transmission and Distribution Conference and Exposition: Asia and Pacific, 2005, pp. 1-6, doi: 10.1109/TDC.2005.1546838.

[22] H. H. Zeineldin, Y. A. I. Mohamed, V. Khadkikar and V. R. Pandi, "A Protection Coordination Index for Evaluating Distributed Generation Impacts on Protection for Meshed Distribution Systems," in IEEE Transactions on Smart Grid, vol. 4, no. 3, pp. 1523-1532, Sept. 2013, doi: 10.1109/TSG.2013.2263745.

[23] D. Eltigani and S. Masri, "Challenges of integrating renewable energy sources to smart grids: A review," Renew Sustain Energy Rev, vol. 52, pp. 770-780, 2015, doi: 10.1016/j.rser.2015.07.140.

[24] M.M. Eissa, "Protection techniques with renewable resources and smart grids - a survey," Renew Sustain Energy Rev, vol. 52, pp. 1645-1667, 2015, doi: 10.1016/j.rser.2015.08.031.

[25] I. Xyngi and M. Popov, "An Intelligent Algorithm for the Protection of Smart Power Systems," in IEEE Transactions on Smart Grid, vol. 4, no. 3, pp. 1541-1548, Sept. 2013, doi: 10.1109/TSG.2013.2244621.

[26] M. R. Islam and H. A. Gabbar, "Analysis of Microgrid protection strategies," 2012 International Conference on Smart Grid (SGE), 2012, pp. 1-6, doi: 10.1109/SGE.2012.6463969.

[27] R. Shah R, N. Mithulananthan, R. C. Bansal, and V. K. Ramachandaramurthy, "A review of key power system stability challenges for large-scale PV integration," Renew Sustain Energy Rev, vol. 41, pp. 1423-1436, 2015, doi: 10.1016/j.rser.2014.09.027.

[28] P. Mahat, Z. Chen, B. Bak-Jensen and C. L. Bak, "A Simple Adaptive Overcurrent Protection of Distribution Systems with Distributed Generation," in IEEE Transactions on Smart Grid, vol. 2, no. 3, pp. 428-437, Sept. 2011, doi: 10.1109/TSG.2011.2149550.

[29] H. H. Zeineldin, E. F. El-saadany and M. M. A. Salama, "Distributed Generation Micro-Grid Operation: Control and Protection," 2006 Power Systems Conference: Advanced Metering, Protection, Control, Communication, and Distributed Resources, 2006, pp. 105-111, doi: 10.1109/PSAMP.2006.285379.

[30] J. Kennedy, P. Ciufo and A. Agalgaonkar, "A review of protection systems for distribution networks embedded with renewable generation," Renewable and Sustainable Energy Reviews, vol. 58, pp. 1308-1317, 2016, doi: 10.1016/j.rser.2015.12.258.

[31] S. Voima, K. Kauhaniemi and H. Laaksonen, "Novel protection approach for MVMicrogrid," in CIRED 21st International Conference on Electricity Distribution, 2011, P. 0430.

[32] X. Liu, M. Shahidehpour, Z. Li, X. Liu, Y. Cao and W. Tian, "Protection Scheme for Loop-Based Microgrids," in IEEE Transactions on Smart Grid, vol. 8, no. 3, pp. 1340-1349, May 2017, doi: 10.1109/TSG.2016.2626791.

[33] X. Lin, Q. Wang, Y. Li and M. Xu, "Research on DG distribution network protection based on topological analysis and power automatic recovery scheme," 2016 International Conference on Cogeneration, Small Power Plants and District Energy (ICUE), 2016, pp. 1-6, doi: 10.1109/COGEN.2016.7728957.

[34] O. A. Gashteroodkhani, M. Majidi and M. Etezadi-Amoli, "A combined deep belief network and time-time transform based intelligent protection Scheme for microgrids," Electric Power Systems Research, vol. 182, pp. 106239, 2020, doi: 10.1016/j.epsr.2020.106239.

[35] Energy Storage Association, "Unleashing the Power of Energy Storage," 2013, [Online]. Available: http://energystorage.org/energy-storage.

[36] D. M. Bui and Shi-Lin Chen, "Fault protection solutions appropriately proposed for ungrounded low voltage AC microgrids: Review and proposals," Renewable and Sustainable Energy Reviews, vol. 75, pp. 1156-1174, 2017, doi: 10.1016/j.rser.2016.11.097.

[37] N. Jayawarna and M. Barnes, "Central storage unit response requirement in 'good citizen' Microgrid," 2009 13th European Conference on Power Electronics and Applications, 2009, pp. 1-10.

[38] A. Oudalov et al., Novel Protection Systems for Microgrids, TC2 Technical Requirements for Network Protection, Contract No. SES6-019864, Partial Report, 2009.

[39] S. Mirsaeidi, D. M. Said, M.W. Mustafa, M.H. Habibuddin, K. Ghaffari, "Progress and problems in micro-grid protection schemes," Renewable and Sustainable Energy Reviews, vol. 37, pp. 834-839, 2014, doi: 10.1016/j.rser.2014.05.044.

[40] T. S. Ustun, C. Ozansoy and A. Zayegh, "A central microgrid protection system for networks with fault current limiters," 2011 10th International Conference on Environment and Electrical Engineering, 2011, pp. 1-4, doi: 10.1109/EEEIC.2011.5874575. 
[41] N. Jayawarna, C. Jones, M. Barnes and N. Jenkins, "Operating MicroGrid Energy Storage Control during Network Faults," 2007 IEEE International Conference on System of Systems Engineering, 2007, pp. 1-7, doi: 10.1109/SYSOSE.2007.4304254.

[42] R. Arghandeh, M. Pipattanasomporn and S. Rahman, "Flywheel Energy Storage Systems for Ride-through Applications in a Facility Microgrid," in IEEE Transactions on Smart Grid, vol. 3, no. 4, pp. 1955-1962, Dec. 2012, doi: 10.1109/TSG.2012.2212468.

[43] J. M. Guerrero, M. Chandorkar, T. Lee and P. C. Loh, "Advanced Control Architectures for Intelligent MicrogridsPart I: Decentralized and Hierarchical Control," in IEEE Transactions on Industrial Electronics, vol. 60, no. 4, pp. 1254-1262, April 2013, doi: 10.1109/TIE.2012.2194969.

[44] C. Li, P. Rakhra, P. Norman, P. Niewczas, G. Burt and P. Clarkson, "Modulated Low Fault-Energy Protection Scheme for DC Smart Grids," in IEEE Transactions on Smart Grid, vol. 11, no. 1, pp. 84-94, Jan. 2020, doi: 10.1109/TSG.2019.2917540.

[45] G. Nayak and S. Nath, "Effect of power electronic protections of inverters on protection of micro-grids," 2016 IEEE 6th International Conference on Power Systems (ICPS), 2016, pp. 1-6, doi: 10.1109/ICPES.2016.7584122.

[46] H. Laaksonen and K. Kauhaniemi, "Fault type and location detection in islanded Microgrid with different control methods based converters," in CIRED $19^{\text {th }}$ International Conference on Electricity Distribution, 2007, P. 0372.

[47] T. Loix, T. Wijnhoven and G. Deconinck, "Protection of microgrids with a high penetration of inverter-coupled energy sources," 2009 CIGRE/IEEE PES Joint Symposium Integration of Wide-Scale Renewable Resources Into the Power Delivery System, 2009, pp. 1-6.

[48] R.H. Lasseter et al., "Integration of Distributed Energy Resources: The CERTS MicroGrid Concept," Consultant Report prepared for the California Energy Commission, 2003.

[49] B. J. Brearley and R.R. Prabu, "A review on issues and approaches for microgrid protection," Renewable and Sustainable Energy Reviews, vol. 67, pp. 988-997, 2017, doi: 10.1016/j.rser.2016.09.047.

[50] C. J. Mozina, "Interconnection protection of IPP generators at commercial/industrial facilities," in IEEE Transactions on Industry Applications, vol. 37, no. 3, pp. 681-688, May-June 2001, doi: 10.1109/28.924745.

[51] C. J. Mozina, "Interconnect protection of dispersed generators," 2001 IEEE/PES Transmission and Distribution Conference and Exposition. Developing New Perspectives (Cat. No.01CH37294), 2001, vol.2, pp. 709-723, doi: 10.1109/TDC.2001.971326.

[52] Mozina, "Distributed Generator Interconnect Protection Practices," 2005/2006 IEEE/PES Transmission and Distribution Conference and Exhibition, 2006, pp. 1164-1170, doi: 10.1109/TDC.2006.1668670.

[53] J. A. Martinez and J. Martin-Arnedo, "Impact of distributed generation on distribution protection and power quality," 2009 IEEE Power and Energy Society General Meeting, 2009, pp. 1-6, doi: 10.1109/PES.2009.5275777.

[54] W. Jiang, Z. He and Z. Bo, "The Overview of Research on Microgrid Protection Development," 2010 International Conference on Intelligent System Design and Engineering Application, 2010, pp. 692-697, doi: 10.1109/ISDEA.2010.69.

[55] A. Kaur, J. Kaushal, P. Basak, "A review on microgrid central controller," Renewable and Sustainable Energy Reviews, vol. 55, pp. 338-345, 2016, doi: 10.1016/j.rser.2015.10.141.

[56] J. K. Tailor and A. H. Osman, "Restoration of fuse-recloser coordination in distribution system with high DG penetration," 2008 IEEE Power and Energy Society General Meeting - Conversion and Delivery of Electrical Energy in the 21st Century, 2008, pp. 1-8, doi: 10.1109/PES.2008.4596422.

[57] "IEEE Guide for Design, Operation, and Integration of Distributed Resource Island Systems with Electric Power Systems," in IEEE Std 1547.4-2011, pp.1-54, Jul 2011, doi: 10.1109/IEEESTD.2011.5960751.

[58] B. Kroposki, R. Lasseter, T. Ise, S. Morozumi, S. Papathanassiou and N. Hatziargyriou, "Making microgrids work," in IEEE Power and Energy Magazine, vol. 6, no. 3, pp. 40-53, May-June 2008, doi: 10.1109/MPE.2008.918718.

[59] H. Laaksonen, K. Kauhaniemi and S. Voima S, "Protection system for future LV Microgrids," in CIRED 21st International Conference on Electricity Distribution, 2011, p. 0431.

[60] W. E. Feero, D. C. Dawson, J. Stevens, Protection Issues of the MicroGrid Concept, CERTS, Report, Mar 2002.

[61] M. Barnes et al., "Real-World MicroGrids-An Overview," 2007 IEEE International Conference on System of Systems Engineering, 2007, pp. 1-8, doi: 10.1109/SYSOSE.2007.4304255.

[62] A. Oudalov and A. Fidigatti, "Adaptive network protection in microgrids," International Journal of Distributed Energy Resources, vol. 5, no. 3, pp. 201-226, 2009.

[63] B. Kroposki et al., "Development of a High-Speed Static Switch for Distributed Energy and Microgrid Applications," 2007 Power Conversion Conference-Nagoya, 2007, pp. 1418-1423, doi: 10.1109/PCCON.2007.373150.

[64] M. T. Aung and J. V. Milanovic, "The influence of transformer winding connections on the propagation of voltage sags," in IEEE Transactions on Power Delivery, vol. 21, no. 1, pp. 262-269, Jan. 2006, doi: 10.1109/TPWRD.2005.855446. 
[65] P. Tatcho, H. Li, Y. Jiang and L. Qi, "A Novel Hierarchical Section Protection Based on the Solid State Transformer for the Future Renewable Electric Energy Delivery and Management (FREEDM) System," in IEEE Transactions on Smart Grid, vol. 4, no. 2, pp. 1096-1104, June 2013, doi: 10.1109/TSG.2012.2207412.

[66] T. Zhao, J. Zeng, S. Bhattacharya, M. E. Baran and A. Q. Huang, "An average model of solid state transformer for dynamic system simulation," 2009 IEEE Power and Energy Society General Meeting, 2009, pp. 1-8, doi: 10.1109/PES.2009.5275542.

[67] X. She, A. Q. Huang and R. Burgos, "Review of Solid-State Transformer Technologies and Their Application in Power Distribution Systems," in IEEE Journal of Emerging and Selected Topics in Power Electronics, vol. 1, no. 3, pp. 186-198, Sept. 2013, doi: 10.1109/JESTPE.2013.2277917.

[68] W. Huang, T. Nengling, X. Zheng, C. Fan, X. Yang and B. J. Kirby, "An Impedance Protection Scheme for Feeders of Active Distribution Networks," in IEEE Transactions on Power Delivery, vol. 29, no. 4, pp. 1591-1602, Aug. 2014, doi: 10.1109/TPWRD.2014.2322866.

[69] O. Alexandre, "Advanced architectures and control concepts for more microgrids," 2009. [Online]. Available: http://www.microgrids.eu/documents/esr.pdf

[70] E. Coster, J. Myrzik and W. Kling, Effect of DG on distribution grid Protection, 2010. [Online]. Available: $\mathrm{http} / / / \mathrm{www}$.intechopen.com/books/distributed generation.pdf.

[71] L. Che, M. E. Khodayar and M. Shahidehpour, "Adaptive Protection System for Microgrids: Protection practices of a functional microgrid system.," in IEEE Electrification Magazine, vol. 2, no. 1, pp. 66-80, March 2014, doi: 10.1109/MELE.2013.2297031.

[72] S. A. Gopalan, V. Sreeram and H. H.C. Iu, "A review of coordination strategies and protection schemes for Microgrids," Renewable and Sustainable Energy Reviews, vol. 32, pp. 222-228, 2014, doi: 0.1016/j.rser.2014.01.037.

[73] R. M. Cuzner and G. Venkataramanan, "The Status of DC Micro-Grid Protection," 2008 IEEE Industry Applications Society Annual Meeting, 2008, pp. 1-8, doi: 10.1109/08IAS.2008.382.

[74] J. J. Justo, F. Mwasilu, J. Lee, Jin-Woo Jung, " AC-microgrids versus DC-microgrids with distributed energy resources: A review," Renew Sustain Energy Rev, vol. 24, pp. 387-405, 2013, doi: 10.1016/j.rser.2013.03.067.

[75] J. Park, J. Candelaria, L. Ma and K. Dunn, "DC Ring-Bus Microgrid Fault Protection and Identification of Fault Location," in IEEE Transactions on Power Delivery, vol. 28, no. 4, pp. 2574-2584, Oct. 2013, doi: 10.1109/TPWRD.2013.2267750.

[76] S. M. Brahma and A. A. Girgis, "Development of adaptive protection scheme for distribution systems with high penetration of distributed generation," in IEEE Transactions on Power Delivery, vol. 19, no. 1, pp. 56-63, Jan. 2004, doi: 10.1109/TPWRD.2003.820204.

[77] "IEEE Standard for Interconnecting Distributed Resources with Electric Power Systems," in IEEE Std 1547-2003, vol., no., pp.1-28, 28 July 2003, doi: 10.1109/IEEESTD.2003.94285.

[78] M. A. Zamani, A. Yazdani and T. S. Sidhu, "A Communication-Assisted Protection Strategy for Inverter-Based Medium-Voltage Microgrids," in IEEE Transactions on Smart Grid, vol. 3, no. 4, pp. 2088-2099, Dec. 2012, doi: 10.1109/TSG.2012.2211045.

[79] Bin Li, Yongli Li, Zhiqian Bo and A. Klimek, "Design of protection and control scheme for microgrid systems," 2009 44th International Universities Power Engineering Conference (UPEC), 2009, pp. 1-5.

[80] M. P. Nthontho, S. P. Chowdhury, S. Winberg and S. Chowdhury, "Protection of domestic solar photovoltaic based microgrid," 11th IET International Conference on Developments in Power Systems Protection (DPSP 2012), 2012, pp. 1-6, doi: 10.1049/cp.2012.0137.

[81] H. Zayandehroodi, A. Mohamed, H. Shareef, M. Mohammadjafari and M. Farhoodnea, "A novel protection coordination strategy using back tracking algorithm for distribution systems with high penetration of DG," 2012 IEEE International Power Engineering and Optimization Conference Melaka, Malaysia, 2012, pp. 187-192, doi: 10.1109/PEOCO.2012.6230858.

[82] L. Wang and S. H. Hyun, "A new fault location method for distribution system under smart grid environment," Proceedings of 2011 6th International Forum on Strategic Technology, 2011, pp. 469-472, doi: 10.1109/IFOST.2011.6021065.

[83] L. Wang et al., "Adaptive protection and control strategy for interfacing wind generators to distribution grids," 2008 International Conference on Electrical Machines and Systems, 2008, pp. 2478-2483.

[84] A. Zamani, T. Sidhu and A. Yazdani, "A strategy for protection coordination in radial distribution networks with distributed generators," IEEE PES General Meeting, 2010, pp. 1-8, doi: 10.1109/PES.2010.5589655.

[85] J. A. Sa'ed, S. Favuzza, M. G. Ippolito and F. Massaro, "An investigation of protection devices coordination effects on distributed generators capacity in radial distribution systems," 2013 International Conference on Clean Electrical Power (ICCEP), 2013, pp. 686-692, doi: 10.1109/ICCEP.2013.6586928. 
[86] Z. Liu, H. K. Hoidalen and M. M. Saha, "An intelligent coordinated protection and control strategy for distribution network with wind generation integration," in CSEE Journal of Power and Energy Systems, vol. 2, no. 4, pp. 23-30, December 2016, doi: 10.17775/CSEEJPES.2016.00045.

[87] Babu PS, Kumar SVJ, Chaitanya PRK. "Digital relay based adaptive protection for distributed systems with distributed generation," Int J Energy Science, vol. 1, no. 2, 72-77, 2011.

[88] J. Ma, C. Mi, T. Wang, J. Wu and Z. Wang, "An adaptive protection scheme for distributed systems with distributed generation," 2011 IEEE Power and Energy Society General Meeting, 2011, pp. 1-6, doi: 10.1109/PES.2011.6039832.

[89] H. Wan, K. P. Wong and C. Y. Chung, "Multi-agent application in protection coordination of power system with distributed generations," 2008 IEEE Power and Energy Society General Meeting - Conversion and Delivery of Electrical Energy in the 21st Century, 2008, pp. 1-6, doi: 10.1109/PES.2008.4596261.

[90] N. Hatziargyriou, Microgrids: Architectures and Control, John Wiley and Sons, West Sussex, UK, 2013.

[91] M. M. Rana, L. Li and S. W. Su, "Microgrid protection and control through reliable smart grid communication systems," 2016 14th International Conference on Control, Automation, Robotics and Vision (ICARCV), 2016, pp. 1-6, doi: 10.1109/ICARCV.2016.7838766.

[92] M. Geidl, "Protection of power systems with distributed generation: state of art," in Technical Rep., ETH, Zurich, Switz., 2005. [Online]. Available: https://doi.org/10.3929/ethz-a-005009366.

[93] Y. Feng, B. Duan, C. Tan and Z. Yao, "A settings tracking and providing scheme for differential protection based on machine learning," 2015 IEEE Innovative Smart Grid Technologies - Asia (ISGT ASIA), 2015, pp. 1-5, doi: 10.1109/ISGT-Asia.2015.7387013.

[94] IEC, Communication networks and systems in substations Ed 2: Part 7-2: Basic information and communication structure-Abstract communication service interface (ACSI), IEC Std. 61850-2-4, Aug. 2010.

[95] S. A. A. Shahriari, M. Abapour, A. Yazdian and M. R. Haghifam, "Minimizing the impact of distributed generation on distribution protection system by solid state fault current limiter," IEEE PES TandD 2010, 2010, pp. 1-7, doi: 10.1109/TDC.2010.5484241.

[96] J. R. S. S. Kumara, A. Atputharajah, J. B. Ekanayake and F. J. Mumford, "Over current protection coordination of distribution networks with fault current limiters," 2006 IEEE Power Engineering Society General Meeting, 2006, pp. 8 pp.-, doi: 10.1109/PES.2006.1709251.

[97] Ł. Huchel and H. H. Zeineldin, "Planning the Coordination of Directional Overcurrent Relays for Distribution Systems Considering DG," in IEEE Transactions on Smart Grid, vol. 7, no. 3, pp. 1642-1649, May 2016, doi: 10.1109/TSG.2015.2420711.

[98] W. El-Khattam and T. S. Sidhu, "Restoration of Directional Overcurrent Relay Coordination in Distributed Generation Systems Utilizing Fault Current Limiter," in IEEE Transactions on Power Delivery, vol. 23, no. 2, pp. 576-585, April 2008, doi: 10.1109/TPWRD.2008.915778.

[99] M. Khederzadeh, "Application of TCSC to restore directional overcurrent relay coordination in systems with distributed generation," CIRED 2009 - 20th International Conference and Exhibition on Electricity Distribution Part 1, 2009, pp. 1-4, doi: 10.1049/cp.2009.0515.

[100] W. El-Khattam and T.S. Sidhu, "Resolving the impact of distributed renewable generation on directional overcurrent relay coordination: a case study," IET Renew. Power Gener, vol. 3, no. 4, pp. 415-425, 2009, doi: 10.1049/iet-rpg.2008.0015.

[101] T. Ghanbari and E. Farjah, "Unidirectional Fault Current Limiter: An Efficient Interface Between the Microgrid and Main Network," in IEEE Transactions on Power Systems, vol. 28, no. 2, pp. 1591-1598, May 2013, doi: 10.1109/TPWRS.2012.2212728.

[102] T. Ghanbari and E. Farjah, "Development of an Efficient Solid-State Fault Current Limiter for Microgrid," in IEEE Transactions on Power Delivery, vol. 27, no. 4, pp. 1829-1834, Oct. 2012, doi: 10.1109/TPWRD.2012.2208230.

[103] R. M. Kamel, A. Chaouachi and K. Nagasaki, "Design and testing of three earthing systems for micro-grid protection during the islanding mode," Smart Grid Renew Energy, vol. 1, no. 3, pp. 132-42, 2010 doi: 10.4236/sgre.2010.13018.

[104] N. El-Naily, S. M. Saad and F. A. Mohamed, "Novel approach for optimum coordination of overcurrent relays to enhance microgrid earth fault protection scheme," Sustainable Cities and Society, vol. 54, pp. 102006, 2020, doi: 2020.

[105] Y. Wang, Z. Yu, J. He, S. Chen, R. Zeng and B. Zhang, "Performance of Shipboard Medium-Voltage DC System of Various Grounding Modes Under Monopole Ground Fault," in IEEE Transactions on Industry Applications, vol. 51, no. 6, pp. 5002-5009, Nov.-Dec. 2015, doi: 10.1109/TIA.2015.2427119.

[106] M. Farhadi and O. A. Mohammed. "Protection of multi-terminal and distributed DC systems: Design challenges and techniques," Electric Power Systems Research, vol. 143, pp. 715-727, 2017, doi: 10.1016/j.epsr.2016.10.038. 
[107] J. Park, "Ground Fault Detection and Location for Ungrounded DC Traction Power Systems," in IEEE Transactions on Vehicular Technology, vol. 64, no. 12, pp. 5667-5676, Dec. 2015, doi: 10.1109/TVT.2015.2388785.

[108] "IEEE Recommended Practice for $1 \mathrm{kV}$ to $35 \mathrm{kV}$ Medium-Voltage DC Power Systems on Ships," in IEEE Std 1709-2010, pp.1-54, 2 Nov. 2010, doi: 10.1109/IEEESTD.2010.5623440.

\section{BIOGRAPHY OF AUTHOR}

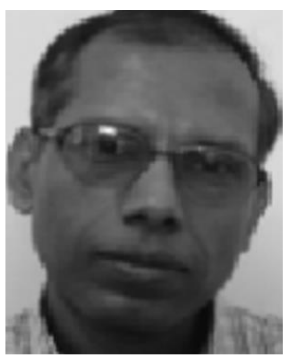

Dr. Ashoke Kumar Basu received the B.E.E., M.Tech. and PhD (Engineering) degrees from Jadavpur University, Kolkata, India. He is currently an Associate Professor in the Department of Electrical Engineering at The Neotia University, Kolkata, India. His Research interests are in the fields of Microgrids, Optimization and Economic and Environment. Dr. Basu is a Life Member of the Institute of Engineers (India). 